\title{
Inhibition of lung cancer growth and metastasis by DHA and its metabolite, RvD1, through miR-138-5p/FOXC1 pathway
}

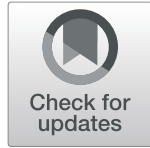

Xiaoming Bai ${ }^{1}$, Jiaofang Shao ${ }^{2}$, Sujin Zhou ${ }^{3}$, Zhenggang Zhao ${ }^{3}$, Fanghong Li ${ }^{3}$, Rong Xiang ${ }^{4}$, Allan Z. Zhao ${ }^{3 *}$ and Jinshun $\operatorname{Pan}^{5^{*}}$ (1)

\begin{abstract}
Background: Non small cell lung cancer (NSCLC) is one of the most common cancers in the world. DHA is known to be capable of suppressing NSCLC cell proliferation and metastasis. However, the mechanisms by which DHA exhibits its antitumor effects are unknown. Here we aimed to identify the effects and mechanisms of DHA and its metabolites on lung cancer cell growth and invasion.

Methods: As measures of cell proliferation and invasion ability, the cell viability and transwell assays were used in vitro. Transgenic mfat-1 mice, which convert $\omega$-6 PUFAs to $\omega$-3 PUFAs, were used to detect the effect of endogenous DHA on tumor transplantation. An LC - MS/MS analysis identified the elevation of several eicosanoid metabolites of DHA. By using qPCR miRNA microarray, online prediction software, luciferase reporter assays and Western blot analysis, we further elucidated the mechanisms.

Results: Addition of exogenous DHA inhibited the growth and invasion in NSCLC cells in vitro. Endogenously produced DHA attenuated LLC-derived tumor growth and metastasis in the transgenic mfat-1 mice. Among the elevation of DHA metabolites, resolvin D1 (RvD1) significantly contributed to the inhibition in cell growth and invasion. MiRNA microarray revealed that the level of miR-138-5p was significantly increased after RvD1 treatment. MiR-138-5 $p$ mimics decreased cell viability and invasion; while miR-138-5p inhibitor abolished RvD1-mediated suppression of cell viability and invasion. The expression of FOXC1 was significantly reduced upon overexpression of miR-138-5p while luciferase reporter assay showed that FOXC1 was a direct target of miR-138-5p. In vivo, endogenous DHA by the mfat-1 transgene enhanced miR-138-5p expression and decreased FOXC1 expression. Furthermore, overexpression of FOXC1 reversed the inhibition in cell viability and invasion induced by RvD1 treatment.
\end{abstract}

Conclusions: These data identified the RvD1/miR-138-5p/FOXC1 pathway as a novel mechanism by DHA and its metabolite, RvD1, and the potential of targeting such pathway as a therapeutic strategy in treating NSCLC.

Keywords: Resolvin D1, miR-138-5p, FOXC1, Growth and invasion, Lung cancer

\footnotetext{
*Correspondence: panjinshun@njmu.edu.cn; azzhao@gdut.edu.cn

${ }^{3}$ School of Biomedical and Pharmaceutical Sciences, Guangdong University

of Technology, Guangzhou 510006, People's Republic of China

${ }^{5}$ Department of Biotherapy, The Second Affiliated Hospital, Nanjing Medical

University, Nanjing 210011, People's Republic of China

Full list of author information is available at the end of the article
}

(c) The Author(s). 2019 Open Access This article is distributed under the terms of the Creative Commons Attribution 4.0 International License (http://creativecommons.org/licenses/by/4.0/), which permits unrestricted use, distribution, and reproduction in any medium, provided you give appropriate credit to the original author(s) and the source, provide a link to the Creative Commons license, and indicate if changes were made. The Creative Commons Public Domain Dedication waiver (http://creativecommons.org/publicdomain/zero/1.0/) applies to the data made available in this article, unless otherwise stated. 


\section{Background}

Lung cancer is the most common cancer in both incidence and death rate, with non-small cell lung cancer (NSCLC) and small-cell lung cancer accounting for 85 and 15\% of the reported cases, respectively [1-3]. Despite advances in detection and improvements to standard of care, NSCLC is often diagnosed at an advanced stage and bears poor prognosis [1]. Although a combination of resection and chemotherapy as well as immunotherapy can improve survival, the prognosis of lung cancer is still poor [4].

Docosahexaenoic acid (DHA), an $\omega-3$ polyunsaturated fatty acid (PUFA), is an essential fatty acid [5]. Epidemiological literatures, including cross-sectional and migrational studies, have revealed a protective effect of DHA against the development of various cancers [6-8]. In NSCLC, DHA not only inhibits cancer cell proliferation and migration [9], but also suppresses angiogenesis [10]. Several DHA metabolites have been found to participate in the control of carcinogenesis [10]. For example, resolvin D1 (RvD1), one of DHA metabolites, has been reported to suppress tumor growth in several murine cancer cell lines at the doses 10,000 times lower than DHA [11]. The potential effects and underlying mechanisms of RvD1 on NSCLC cell growth and invasion, however, are completely unknown, apart from inhibiting TGF- $\beta 1$-induced epithelial mesenchymal transition in lung cancer $[12,13]$.

MiRNAs are small, endogenous noncoding RNAs (1823 nucleotides) that post-transcriptionally regulate gene expression by targeting the 3 '-untranslated regions (3'UTR) of mRNAs [14]. Aberrant expression of some miRNAs has been reported to be associated with malignant phenotypes in various cancers, participating in not only cell proliferation, but also invasion and metastasis $[15,16]$. In addition, several miRNAs were involved in the control of cancer cell growth and invasion by DHA metabolites $[9,13]$. Among them, miR-138-5p is postulated as a tumor suppressor. Accordingly, the expression of miR-138-5p is decreased in many cancer tissues, compared with adjacent noncancerous tissues; and reduced expression of miR-138-5p is significantly correlated with patients' clinicopathological factors and poor survival $[17,18]$. Among NSCLC cases, miR-138-5p is involved in the elevation of GADD45A and inhibits cell growth [19]. However, little is known about the relationship between DHA and miR-138-5p.

A series of recent studies involving the usage of a transgenic genetic model, fat-1 (or mfat-1) transgenic mice, have shed new light into the mechanisms underlying the protective effects of $\omega-3$ PUFAs [20]. The fat-1 transgenic mice, initially generated in Kang's lab [21, 22] (and later the mfat-1 mouse model independently designed by our group [23]) carry a globally expressed $C$. elegans fat-1 transgene that encodes an $\omega-3$ fatty acid desaturase. The FAT-1 enzyme can convert $\omega-6$ PUFAs to the corresponding $\omega-3$ forms by adding a double bond to the $\omega-3$ position, thus allowing endogenous production of $\omega-3$ PUFAs while reducing the $\omega-6: \omega-3$ ratio in tissues without special dietary adjustment [23, 24]. The fat- 1 transgenic model allows researchers to bypass the traditional lengthy dietary approach of feeding fishoil to the animals, and have been widely applied to the studies related to autoimmune diseases, tumorigenesis, metabolic and cardiovascular diseases, as well as neurological diseases.

In current studies, we found that endogenous DHA produced by mfat-1 gene significantly inhibited cell viability and metastasis, and increased RvD1 production in lung cancer cells. Further, miR-138-5p was upregulated in RvD1-treated lung cancer cells. Herein, we intend to advance the role and mechanisms of DHA and RvD1 on NSCLC growth and metastasis, with the primary focus on miR-138-5p-mediated pathway.

\section{Materials and methods Materials}

Dulbecco's modified Eagle's medium (DMEM) and Lipofectamine 2000 were obtained from Invitrogen (Carlsbad, CA, USA). DHA, EPA, PUFA analytical standards and Matrigel were obtained from Sigma-Aldrich (St. Louis, MO, USA). The protein assay was from Bio-Rad (Hercules, CA, USA). Water-soluble tetrazolium (WST) reagent was from Dojindo Laboratories (Kumamoto, Japan). Electrochemiluminescence (ECL) reagents were obtained from Amersham Biosciences (Piscataway, NJ, USA). The dual-luciferase reporter assay system was obtained from Promega Corporation (Madison, WI, USA). PrimeScript RT Reagent Kit was obtained from TAKARA Bio Inc. (\#RR037A, Shiga, Japan). SYBR Green Master was from Roche Diagnostics (\#04913914001, Indianapolis, IN, USA). Resolvin D1 (RvD1) was obtained from Cayman Chemical Co. (\#10012554, Ann Arbor, Michigan, USA). The following were commercially obtained antibodies: the anti-Akt (\#9272), anti-phospho-Akt (Ser473, \#4060), the anti-Erk1/2 (\#4696), and anti-phospho-Erk1/2 (Thr202/Tyr204, \#8544) antibodies were obtained from Cell Signaling Technology (Danvers, MA, USA); the anti-FOXC1 antibody (\#115201) was obtained from Abcam plc (Cambridge, UK); the anti-GAPDH antibody was obtained from Bioworld Technology (Atlanta, Georgia30,305, USA). EnVision+single reagents (Mouse, Rabbit) were from DAKO (K4000, K4002, Glostrup, Denmark).

\section{Cell culture and reagents}

Human lung cancer cell lines (A549 and H1299) and mouse lung cancer cell line (LLC) were cultured in Dulbecco's modified Eagle's medium (DMEM; Gibco) supplemented with $10 \%$ fetal bovine serum (FBS; Gibco), $100 \mathrm{U} / \mathrm{ml}$ penicillin, $100 \mathrm{ng} / \mathrm{ml}$ streptomycin. Human 
embryonic kidney $293 \mathrm{~T}$ (HEK293 T) cells were maintained in DMEM supplemented with 10\% FBS, $100 \mathrm{U} / \mathrm{ml}$ penicillin, $100 \mathrm{ng} / \mathrm{ml}$ streptomycin. All cell lines were maintained in a $37^{\circ} \mathrm{C}$ incubator with $5 \% \mathrm{CO} 2$.

\section{Animals}

All animals (female C57BL/6 J and mfat-1 mice) were treated in accordance with the guidelines of the Institutional Animal Care and Use Committee at Nanjing Medical University. The animals were fed regular diet and water ad libitum, and housed at $22^{\circ} \mathrm{C}$ with a 12-h lightdark cycle. The normal diet was from Xietong Biotechnology Co. Ltd. (Jiangsu, China). All animal studies comply with the ARRIVE guidelines. The mfat- 1 transgenic mice were described in our previous studies [7]. Analyses of $\omega$ 6 and $\omega-3$ PUFA composition in transgenic mice were shown in Additional file 1: Table S1. All above strains of mice have a C57BL/6 genetic background.

\section{Patients and specimens}

Primary surgical specimens were collected from 60 patients (aged from 52 to 83; average, 64) who were diagnosed clinically for squamous cell carcinoma (LUSC) or adenocarcinoma (LUAC), from the Jiangsu Province Hospital and the Nanjing Chest Hospital. None of them had distant metastasis. All of them were approached for participation in the project and the experimental protocols were approved by the Human Ethics Committee of Nanjing Medical University, including any relevant details. Written informed consent was obtained from all the donors for use of these samples in research. The work conforms to the provisions of the Declaration of Helsinki in 1975. Resected specimens were fixed with neutral buffered $10 \%$ formalin and embedded in paraffin blocks. The diagnosis and histological grade of all the cases were confirmed independently by two pathologists based on World Health Organization (WHO) classification.

\section{Plasmid transfections}

The pCMV-based plasmid encoding human FOXC1 was obtained from the nonprofit plasmid repository (Addgene, MA 02139 USA). A549 cells $\left(2 \times 10^{5}\right)$ were seeded and grown in 6 -well culture plates for $24 \mathrm{~h}$ before transfection with the plasmids, or empty vector control $(2 \mu \mathrm{g})$ using Lipofectamine $2000(5 \mu \mathrm{l})$. The efficiency of transfection was assayed by Western blot. The levels of FOXC1 overexpression were evaluated in Additional file 2: Figure S1.

\section{MiRNAs mimics and siRNA transfection}

The miR-138-5p mimics, miR-138-5p inhibitor, and the siRNA targeting FOXC1 (siFOXC1) were obtained from Santa Cruz Biotechnology (Santa Cruz, CA, USA). A549 cells $\left(2 \times 10^{5}\right)$ were plated in 6-well plates and cultured for $24 \mathrm{~h}$. The cells were then transfected with different
RNAs using Lipofectamine 2000. After $48 \mathrm{~h}$, the levels of target proteins were confirmed by Western blot, and the cells were subsequently used for further experiments. The levels of overexpression or inhibition of miR-138 were evaluated by qRT-PCR. The levels of inhibition of FOXC1 expression were determined by Western blot. ${ }^{* * *} P<0.01$ compared to corresponding control groups (Additional file 2: Figure S1).

\section{Overexpression of mfat-1 by lentiviral transfection}

The mfat-1 cDNA, as described previously [7], was synthesized and cloned into the PLJM1 lentivirus vector (Addgene, Palo Alto, CA, USA). PLJM1-mfat-1 or the vehicle plasmids were transfected into HEK293T cells, according to manufacturer's instructions. Lentiviruscontaining supernatant was harvested $48 \mathrm{~h}$ after transfection and used to infect LLC cells.

Total RNA isolation, reverse transcription PCR (RT-PCR) and quantitative real-time PCR analysis

Total RNA was isolated from cells using the Trizol reagent, according to the manufacturer's instructions. For each sample, $0.5 \mu \mathrm{g}$ of RNA was reverse transcribed using the PrimeScript RT Reagent Kit. For the purposes of the RT-PCR or qPCR analysis, GAPDH was used as the reference.

RT-PCR analysis was used to detect the mfat-1 expression in LLC cells and transgenic mice. Forward primer (5' -GGACCTGGTGAAGAGCATCCG- $3^{\prime}$ ) and reverse primer ( $5^{\prime}$-GCCGTCGCAGAAGCCAAAC- $\left.3^{\prime}\right)$ were used to detect mfat-1 mRNA, and an amplified fragment of 438 bp was indicative of the mfat-1 gene (Additional file 2: Figure S1).

Real time PCR analysis was performed using the Power SYBR Green PCR master mix. PCR reaction conditions were: pre-incubation at $95^{\circ} \mathrm{C}$ for $10 \mathrm{~min}(1 \mathrm{cycle}) ; 95^{\circ} \mathrm{C}$ for $15 \mathrm{~s}, 60^{\circ} \mathrm{C}$ for $15 \mathrm{~s}$ and $72^{\circ} \mathrm{C}$ for $30 \mathrm{~s}$ ( 40 cycles). Fluorescence emission data were collected during the annealing step. All treatments and conditions were performed in triplicate to calculate statistical significance.

\section{Western blot}

A549 and LLC cells were treated with pharmacological agents for different length as indicated in the figure legends. The cells were collected into lysis buffer and then cleared by centrifugation at $12,000 \times \mathrm{g}$ for $15 \mathrm{~min}$ at $4{ }^{\circ} \mathrm{C}$. Equal amounts of total proteins $(20 \mu \mathrm{g})$ were separated by SDSPAGE, detected by a standard enhanced-chemiluminescent reaction and analyzed using Image Lab 4.0 analysis software from Bio-Rad.

\section{Cell proliferation and invasion assays}

Cell proliferation assays were performed in 96-well plate. The cells were stained with WST at $37^{\circ} \mathrm{C}$ for $1 \mathrm{~h}$ and 
quantified by the absorbance at $450 \mathrm{~nm}$. Cell invasion assays were performed in 12-well transwell units. After incubation at $37^{\circ} \mathrm{C}$ for $24 \mathrm{~h}$, the cells were fixed with ethanol and then stained with $0.1 \%$ crystal violet. The cells that had invaded to the lower surface of the membrane were photographed by a LeiCa Microscope. Low high power views $(200 \times)$ were selected randomly from each sample in a blind manner. The cells invaded to lower surface of transwell units were solubilized with $10 \%$ acetic acid and quantified by measuring the absorbance at $590 \mathrm{~nm}$.

\section{Gas chromatography analysis of fatty acid compositions} Lipids extraction from cells and tissues were performed according to a previous report [7]. The gas chromatography was done on an Agilent 7890A. Identification of components was done by comparison of retention times with those of PUFA analytical standard.

\section{Metabolomic analysis of eicosanoids}

The LLC cells were seeded in $15 \mathrm{~cm}$ dish $24 \mathrm{~h}$ before adding DHA. $2 \times 10^{7}$ cells were needed for eicosanoid analysis in each sample. Eicosanoid extraction was performed according to a previous report [7]. Chromatographic separation involved an ACQUITY UPLCBEH C18 column consisting of ethylene-bridged hybrid particles. The metabolites were quantified by use of a 5500 QTRAP hybrid triple quadrupole linear ion trap mass spectrometer equipped with a Turbo Ion Spray electrospray ionization (ESI) source.

\section{Tumor allografts models}

Four-week-old female WT and mfat-1 mice were injected with $2 \times 10^{6} / 0.1 \mathrm{ml}$ of LLC cell lines into the flanks subcutaneously. Bi-dimensional tumor measurements were taken every 2 days. Tumor volume was measured along two major axes using callipers. Tumor volume $\left(\mathrm{mm}^{3}\right)$ was calculated as follows: $\mathrm{V}=1 / 2 \mathrm{~L} \times \mathrm{W}^{2}$ (L: length, W: width). Twenty-four days after cancer cells subcutaneous injection, the mice were executed, and the tumor allografts were removed. The tail vein injection was carried out in WT and mfat- 1 mice with $5 \times 10^{5} / 0.3$ $\mathrm{ml}$ of LLC cells. Forty days after tail vein injection, the mice were executed. The lungs and other organs were removed. The specimens were fixed with neutral buffered $10 \%$ formalin and embedded in paraffin blocks. Sections $(4 \mu \mathrm{m})$ of the tumor blocks were used for in situ hybridization and immunohistochemical staining.

\section{In situ hybridization assays}

The RNAscope probe for human and mouse miR-138-5p was hybridized on $4 \mu \mathrm{m}$ slides of human lung cancer masses and mouse tumor allografts following the in situ hybridization assay protocol. Sequential slides were stained with a mouse-specific control probe following the standard protocol. Four high power views $(400 \times)$ were selected randomly from each sample in a blind manner; the level of integrated optical density was estimated using the Image Pro Plus software and presented as mean \pm SEM.

\section{Immunohistochemical staining}

The sections $(4 \mu \mathrm{m})$ of tumor blocks were used for immunohistochemical analysis. Sections were treated with primary anti-FOXC1 antibody with PBS used as a negative control. The slices were photographed by under a LeiCa Microscope and Image Analyze system. Four high power views $(400 \times)$ were selected randomly from each sample in a blind manner; the level of integrated optical density was estimated using the Image Pro Plus software and presented as mean \pm SEM.

\section{Dual-luciferase reporter assay}

The 3'-UTR-luciferase reporter constructs containing the 3 '-UTR region of FOXC1 with the wild-type and mutant binding sites of miR-138-5p were amplified using PCR. The mutant 3'-UTR construct was made by introducing the mismatch mutation into the putative seed regions of FOXC1. A549 cells $\left(1.0 \times 10^{5} /\right.$ well $)$ were seeded in cultured for 24-h in 24-well plates. The cells were then co-transfected with either wild-type (WT1 and WT2) or mutant-type (mut1 and mut2) luciferase reporter plasmids, and equal amounts of miR-138-5p using Lipofectamine2000 according the manufacturer's instruction. Luciferase activities were measured $24 \mathrm{~h}$ after transfection using the Dual Luciferase Reporter Assay System (Promega). Experiments were performed with three independent replicates.

\section{Statistical analysis}

Statistical analysis of the integrated optical density level of pictures was performed using STATA se12.0 software (Stata Corp, Collage Station, TX, USA). The miR-138-5p miRNA expression data and FOXC1 expression data were downloaded from the TCGA database of LUSC and LUAC cancer tissues. The overall survival (OS) was analyzed by the COX Regression Test. The correlation between gene expression and tumor extent (T1-T4), lymph node metastasis (N0-N3) or distant metastasis (M0-M1) was analyzed by Kruskal-Wallis Test or Wilcoxon Test. $P$ value was shown. Other data are presented as mean \pm SEM. $P$-values were calculated by one-way ANOVA for unpaired samples using the GraphPad Prism software. The results were considered significant at ${ }^{*} P<0.05, * * P<0.01$.

\section{Results}

\section{DHA decreases NSCLC cell growth and invasion}

Human lung cancer cell lines, A549 and H1299, and a mouse lung cancer cell line, LLC, were applied to 
evaluate the impact of DHA on cellular growth and invasion. DHA decreased cell viability in all the above lung cancer cells in a dose-dependent manner. Treatment of the cells with $100 \mu \mathrm{M}$ DHA for $24 \mathrm{~h}$ caused a loss of viability up to 70-90\%. Meanwhile, A549, H1299 and LLC cells exhibited a similar reduction of cell invasion following the DHA treatment (Fig. 1a). Then we added another $\omega-3$ PUFAs, EPA, to lung cancer cells, and investigated its effects on cell viability and invasion. However, EPA treatment showed mild antitumor effects in A549 and H1299 (Additional file 3: Figure S2).

As a further step of demonstrating the beneficial effect of DHA against lung cancer development, we infected LLC cells with a lentiviral vector carrying the mfat-1 gene (termed "LLC-mfat-1"cells) whose encoded enzyme could endogenously convert $\omega-6$ PUFAs to $\omega-3$ PUFAs (including DHA and EPA) [20]. A control cell line expressing green fluorescent protein (GFP) was termed LLC-GFP. The expression of mfat-1 allowed more than $50 \%$ increase in endogenous DHA level (from 1.61 to $2.46 \%, P<0.05)$ (Fig. 1b), which coincided with a significantly suppressed cell viability and invasion (Fig. 1c).

The inhibition of lung cancer growth by endogenously elevated DHA was further shown in the cancer model grafts derived from subcutaneously implanted LLC cells in both the wild-type (WT) and mfat-1 transgenic mice. Elevation of tissue contents of $\omega-3$ PUFAs including DHA sharply slowed the growth of the implanted LLC tumor as measured by tumor volumes, and prolonged the survival of tumor-bearing mice (Fig. 1d, e). In

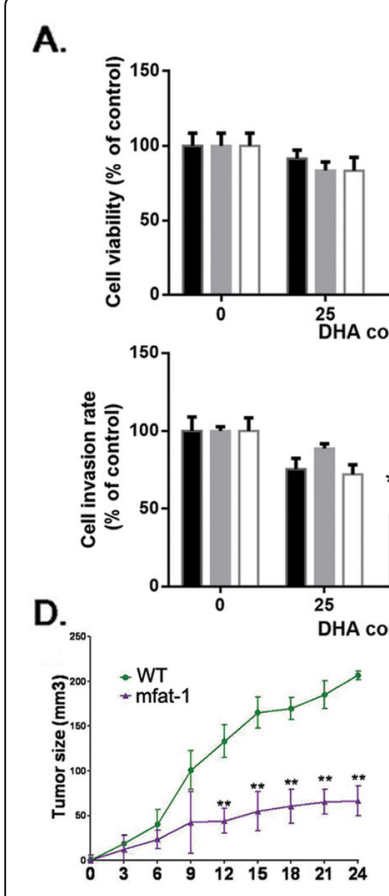

F.

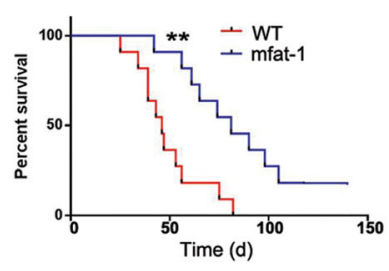

G.

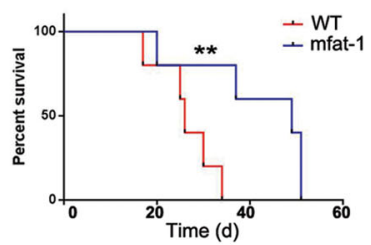

G.

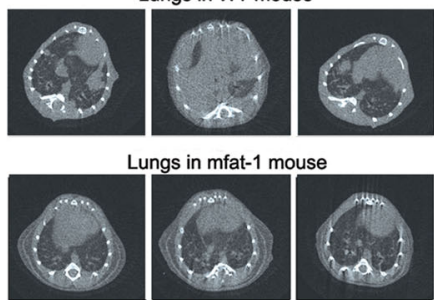

B.

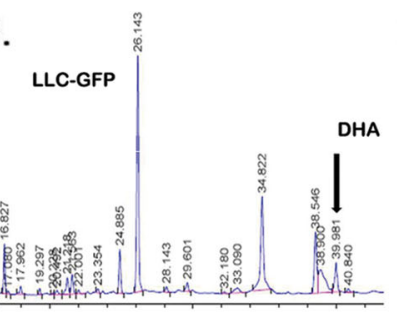

LLC-mfat-1

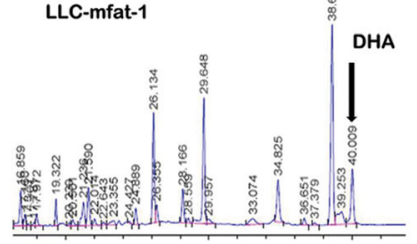

C.
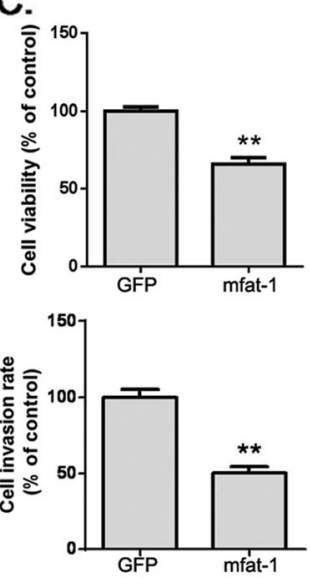

E.
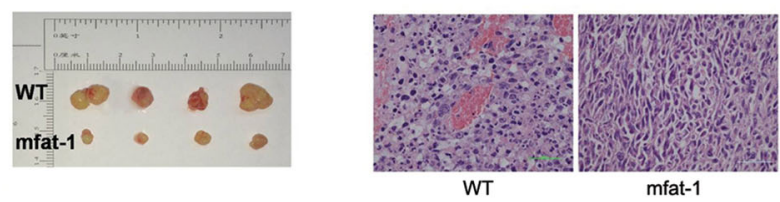

$\mathrm{H}$.

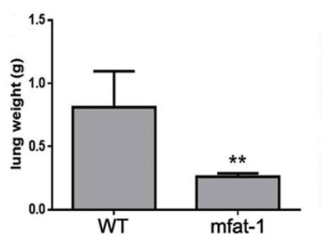

I.

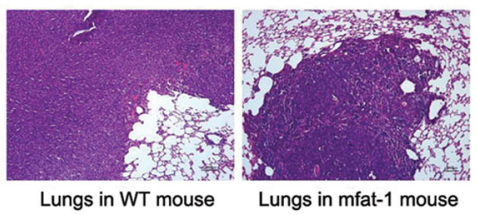

Fig. 1 Exogeneous and endogenous DHA inhibit cell growth, invasion and metastasis of NSCLC cells. a. A549, H1299 or LLC cells were treated with various concentration of $\mathrm{DHA}$, and were subjected to cell growth and invasion assays $(n=4) .{ }^{*}, \#, \$ p<0.05,{ }^{*},{ }^{\# \#,}, \$ p<0.01$ compared to $0 \mu \mathrm{M}$ DHA group. $\mathbf{b}$. LLC cells were transduced with lentivirus carrying the mfat-1 gene, or GFP as a negative control. Components were identified by comparison of retention times with those of PUFA analytical standard. The amount of DHA is expressed as a percentage of all fatty acid peaks. c. LLC-GFP and LLC-mfat-1 were subjected to cell growth and invasion assays $(n=4)$. d. LLC cells were subcutaneously injected into female WT or mfat-1 mice $(n=8)$. Survival of tumor-bearing mice (Right). e. Representative images of implantation tumors (Left). HE staining of tumors (400x) (Right). f. LLC cells were injected into tail veins of female WT or mfat-1 mice $(n=8)$. Survival of tumor-bearing mice. $\mathbf{g}$. $C T$ images of metastatic lung tumors. h. Mass of excised tumors. i. HE staining of tumors (100x) 
metastatic models, the WT and mfat-1 mice were injected with LLC cells through tail veins. During the ensuing observation period, the mfat- 1 mice displayed significantly longer survival time than the control WT mice. After euthanasia, we found endogenous DHA caused lower lungs weight and partial tumor regression (Fig. 1f-i). In the WT mice, the metastatic tumors were identified not only in lungs, but also in submaxillary gland, bone, adrenal gland, and buttock, while the metastatic tumor could only be found in the lungs of the mfat-1 mice, but at much reduced weight and size (Fig. 1h-i, Additional file 4: Figure S3). Thus, DHA, provided exogenously or endogenously, could reduce tumor cell growth, invasion and metastasis in vitro and in vivo.

DHA-derived eicosanoid, RvD1, is involved in DHAmediated suppression of cancer cell growth and invasion To understand the impact of DHA on NSCLC growth and metastasis, we analyzed some of the eicosanoid metabolites induced by DHA treatment. As one would expect, 10 of the 15 identified DHA-derived metabolites through LC-MS/MS assays were increased in LLC cells following DHA treatment or the expression of mfat-1 (Table 1), chief among which, RvD1, was sharply elevated compared with the control group. RvD1 is essentially undetectable in the cultured lung cancer cells, but sharply increased in cells with either exogenous or endogenous DHA treatment. With this knowledge, we evaluated the effects of RvD1 in A549, H1299 and LLC cells. RvD1 decreased cell viability in A549, H1299 and LLC cells in a dose-dependent manner (Fig. 2a, b). At the dose of $200 \mu \mathrm{g} / \mathrm{L}$, RvD1 treatment for $24 \mathrm{~h}$ caused a loss of viability $60 \%$. All the lung cancer cells exhibited a similar reduction in cell invasion following RvD1 treatment (Fig. 2a, b). Furthermore, addition of RvD1 to A549 cells had a profound effect on Akt and Erk1/2 phosphorylation. These results suggested that RvD1 inhibited cell growth and invasion in NSCLC in vitro (Fig. 2c).

\section{RvD1 suppresses lung cancer cell growth and invasion by increasing miR-138-5p expression}

Previous studies have shown that RvD1 regulates the expression of several miRNAs and plays important roles in the regulation of inflammation [25]. Using a human miRNA microarray, we found that the expression levels of many miRNA species were affected by the addition of RvD1 in A549 cells. Among which, the expression of miR-138-5p was sharply elevated with more than a 60 fold increase than that in control cells (Fig. 3a). These results made us investigate miR-138 expression in the cancer specimens derived from LUSC and LUAD in the TCGA miRNA expression database, which covers the patients with different lymphatic metastasis or hematogenous metastasis. In LUSC patients, miR-138 expression was significantly reduced in cases with distant metastasis, and high expression of miR-138 showed longer survival tendency than those with low miR-138 expression (Fig. 3). In LUAD patients, high expression of miR-138 was significantly correlated with longer survival than those with low miR-138 expression. In addition, miR-138 expression was significantly reduced in cases with tumor extents (Fig. 3b).

We found that the mimics of miR-138-5p, after applied to the cultured cells, could decrease cell viability and invasion in A549 cells (Fig. 3c). In contrast,

Table 1 LLC cell DHA metabolite concentration (ng/10 cell) determined by LC-MS/MS

\begin{tabular}{|c|c|c|c|}
\hline Oxylipin & LLC-GFP & LLC-GFP treat with DHA & LLC-mfat-1 \\
\hline$\overline{10-H D O H E}$ & $0.34 \pm 0.20$ & $1072.73 \pm 245.41^{* *}$ & $736.22 \pm 205.21^{* *}$ \\
\hline 10S,17S-DiHDoHE & NP & $8.75 \pm 3.54^{* *}$ & NP \\
\hline 11-HDoHE & NP & $1300.73 \pm 254.98^{* *}$ & NP \\
\hline 13-HDoHE & $0.56 \pm 0.39$ & $734.25 \pm 261.61^{* *}$ & $575.98 \pm 272.13^{* *}$ \\
\hline 14-HDoHE & $0.46 \pm 0.32$ & $454.98 \pm 197.20^{*}$ & $179.32 \pm 92.18^{* *}$ \\
\hline 17-HDoHE & $1.31 \pm 0.74$ & $1674.18 \pm 492.10^{* *}$ & $661.26 \pm 133.4^{* *}$ \\
\hline 20-HDoHE & $1.00 \pm 0.63$ & $2567.3 \pm 438.31^{* *}$ & $822.19 \pm 212.35^{* *}$ \\
\hline 4-HDoHE & $2.93 \pm 1.10$ & $5175.27 \pm 475.64^{* *}$ & $1634.9 \pm 773.01^{* *}$ \\
\hline 7-HDoHE & $0.59 \pm 0.34$ & $2020.17 \pm 293.62^{* *}$ & $536.16 \pm 124.03^{* *}$ \\
\hline 8-HDoHE & $2.57 \pm 1.65$ & $5847.24 \pm 425.41^{* *}$ & $1298.76 \pm 235.18^{* *}$ \\
\hline Maresin & NP & NP & NP \\
\hline RvD1 & NP & $2.18 \pm 0.59^{* *}$ & $1.07 \pm 0.32^{* *}$ \\
\hline RvD2 & NP & NP & NP \\
\hline 16,17-EDP & $0.76 \pm 0.55$ & $1079.19 \pm 333.12^{* *}$ & $343.23 \pm 83.43^{* *}$ \\
\hline 19,20-EDP & $1.43 \pm 0.42$ & $3858.48 \pm 419.96^{* *}$ & $1131.8 \pm 241.57^{* *}$ \\
\hline
\end{tabular}

${ }^{*} P<0.05,{ }^{* *} P<0.01$ compared with LLC-GFP. Data are mean \pm SD. NP No peak, CYP Cytochrome P450 enzymes, COX Cyclooxygenase, LOX Lipoxygenase, $P G$ Prostaglandin 


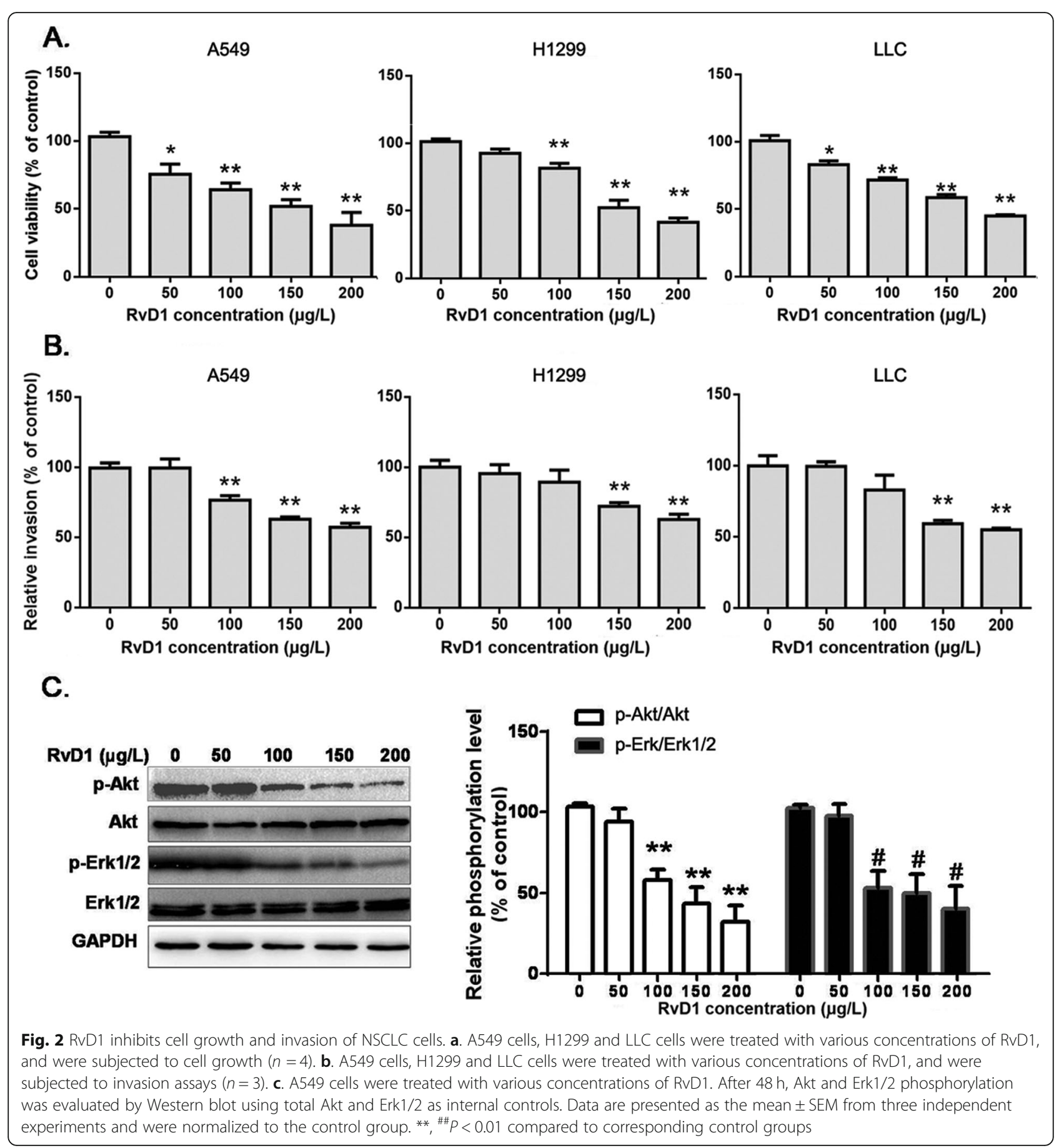

transfection of miR-138-5p inhibitor not only increased cell viability and invasion but, more importantly, largely neutralized RvD1-mediated suppression in cell viability and invasion (Fig. 3c-e). These data indicated that induction of miR-138-5p expression was an important contributing mechanism for the suppressive effect of RvD1 on lung cancer cell growth and invasion. However, addition of miR-138 failed to reverse the inhibitory effect of RvD1 on Akt or Erk1/2 kinases, suggesting the parallel regulation of these two molecular events that can be both important for DHA inhibitory effects on lung cancer growth (Fig. 3f).

MiR-138-5p directly targets FOXC1 expression to reduce lung cancer cell growth and invasion

Bioinformatics analysis suggests that Forkhead Box C1 (FOXC1) is potentially a target of miR-138-5p (www.tar getscan.org/). Indeed, Western blot assays showed that 


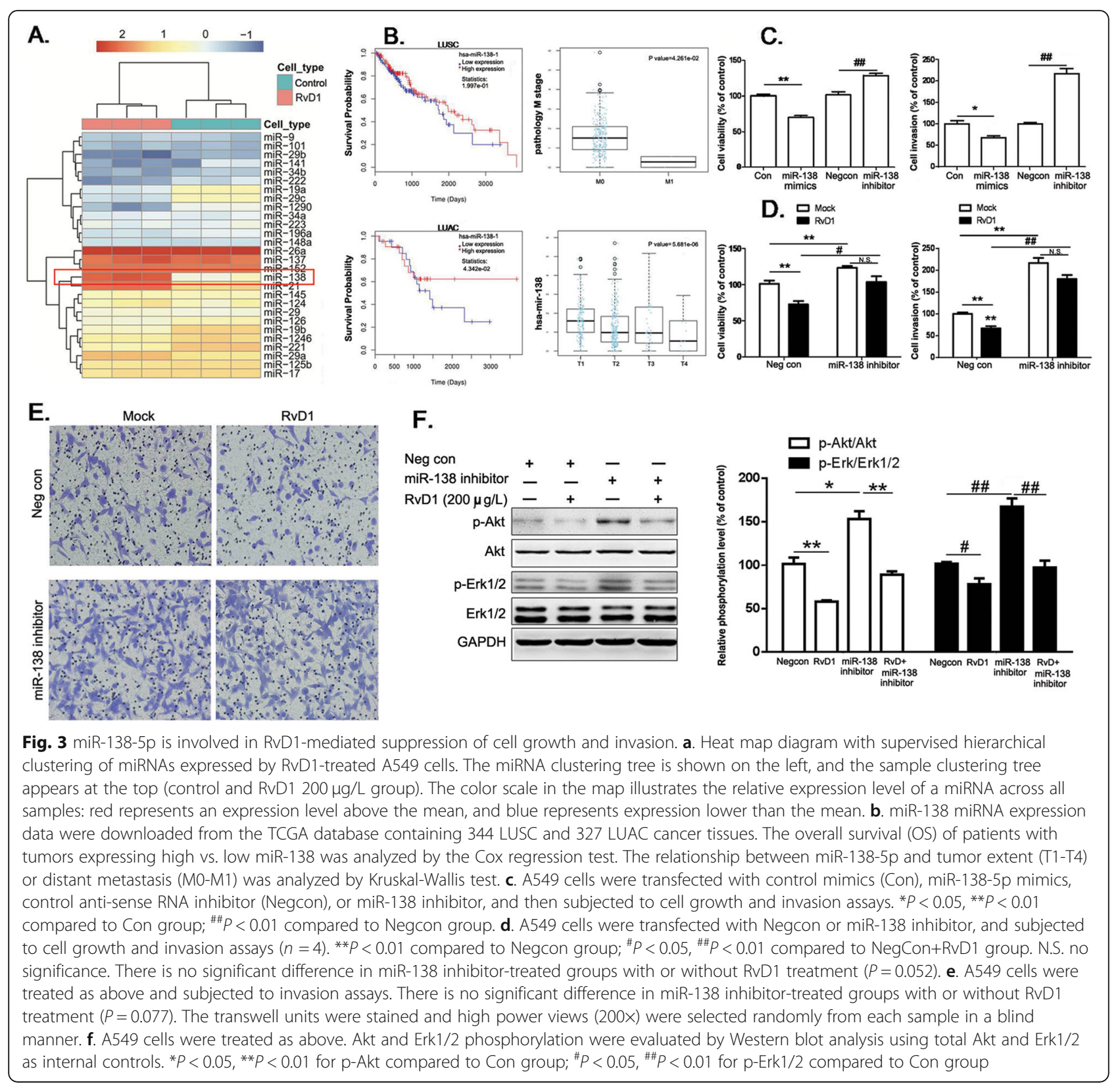

the protein level of FOXC1 was decreased in a dosedependent manner by RvD1 treatment in A549 cells (Fig. 4a); meanwhile, miR-138-5p mimics reduced FOXC1 expression. In contrast, an inhibitor of miR-138$5 \mathrm{p}$, after transfected into the same cell line, significantly increased FOXC1 expression (Fig. 4b). To further confirm these findings, luciferase reporter constructs were made in which the putative binding site in the 3'-UTR regions of FOXC1 (wt) or the same binding site except with three nucleotide substitutes (mut1 and mut2, indicated in Fig. 4c). Transfection of miR-138-5p inhibited the expression of the reporter gene containing the WT, but not the mut1 or mut2, of the 3'-UTR region of
FOXC1 (Fig. 4d), demonstrating that miR-138-5p can specifically target FOXC1 3 '-UTR regions by binding to the target sequences.

Since FOXC1 is highly expressed in many cancers and contributes to cancer cell growth and invasion [26], we also looked into FOXC1 expression in LUSC and LUAD cancer specimens with different tumor extents and lymphatic metastasis in TCGA mRNA expression database. High expression of FOXC1 correlated with poor survival of the patients with LUAD when compared to the patients with low expression of FOXC1 (Fig. 5a). FOXC1 expression was also high in lymphatic metastatic tissues (Fig. 5). Analysis of FOXC1 expression in TCGA 


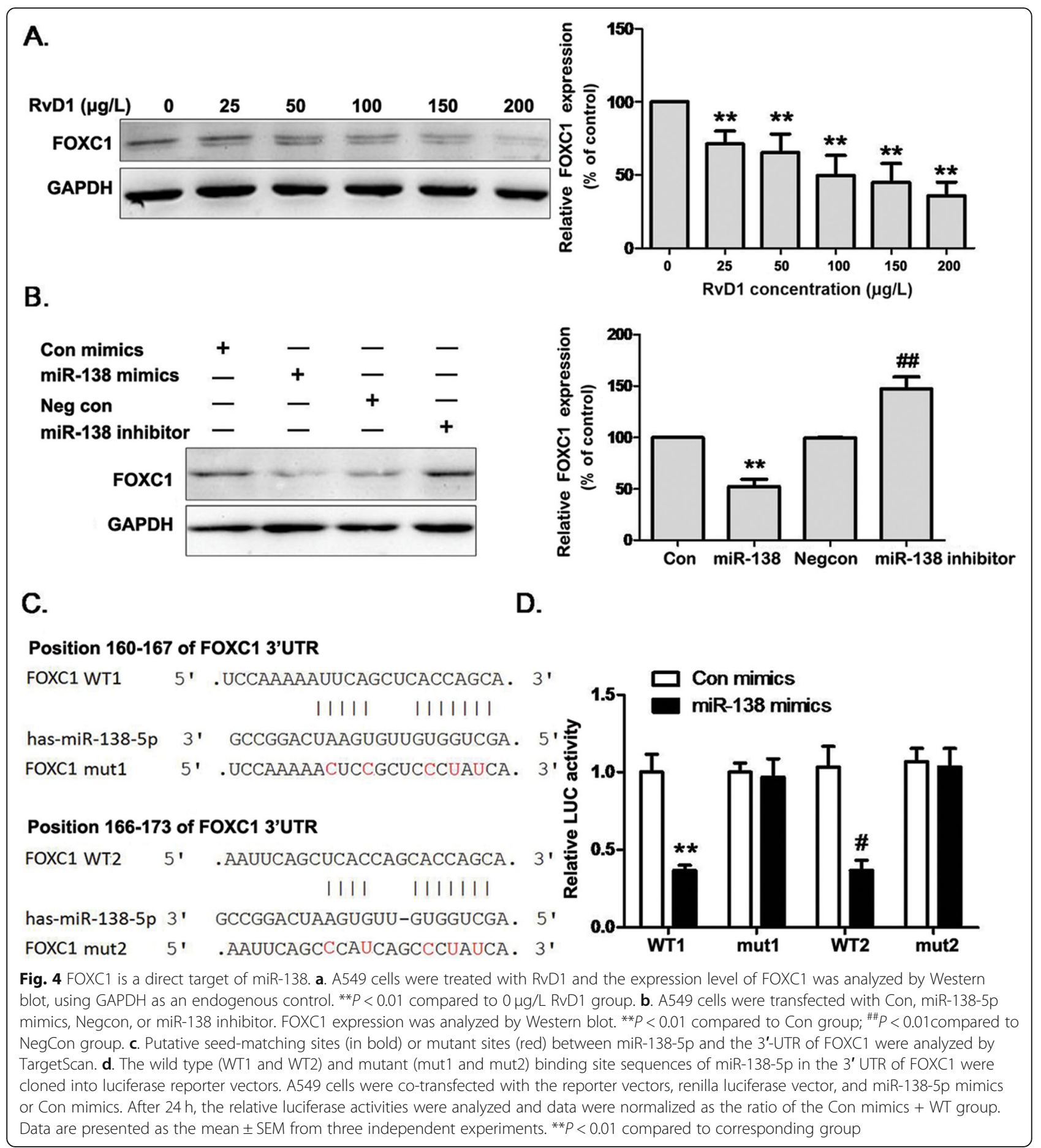

database covering LUSC cases showed a similar tendency correlation between the expression of FOXC1 and survival of patients (Additional file 5: Figure S4). In 60 lung cancer cases (30 LUSC and 30 LUAD), in situ hybridization assays were used to detect miR-138-5p expression, and immunohistochemistry assays were used to detect FOXC1 expression. Figure 5b showed a strong negative correlation existed between the expression levels of miR-138-5p and FOXC1 in both LUAD and LUSC tissues.

To establish the cross regulation of FOXC1 activity by miR-138-5p, A549 cells were transfected with miR-138$5 p$ mimics with or without co-transfection of a CMV promoter-driven FOXC1 construct. Overexpression of FOXC1 not only increased cell viability and invasion, but partially blocked the suppressive effects of miR-138- 


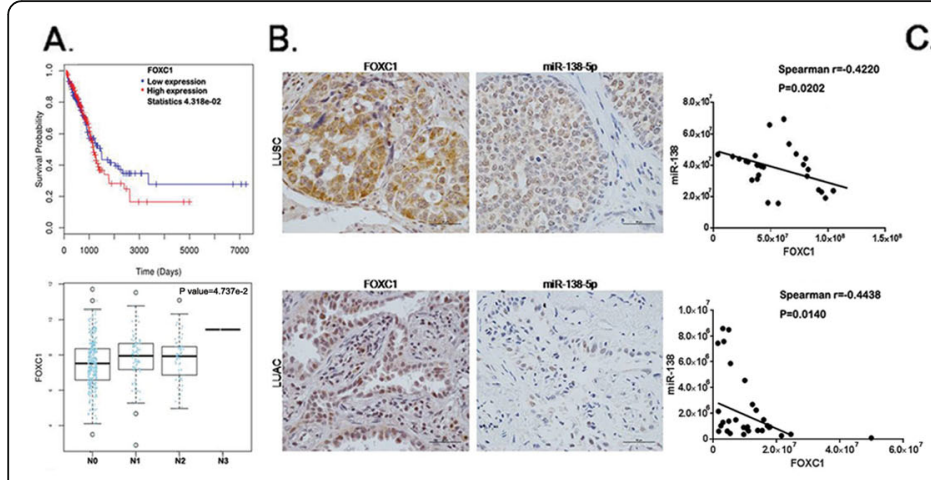

C.

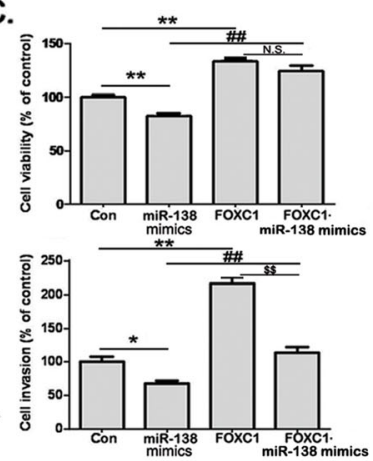

G.

F.
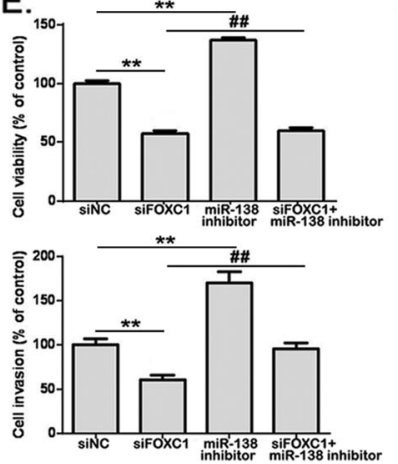

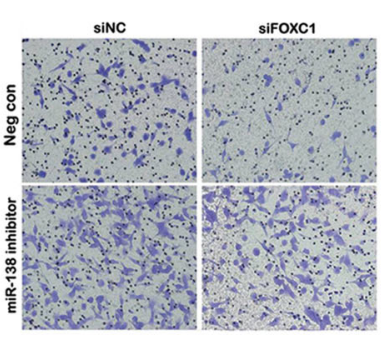

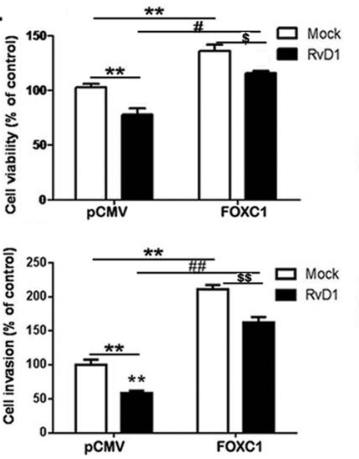

D.

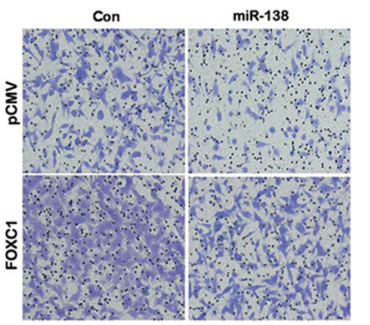

$\mathrm{H}$.
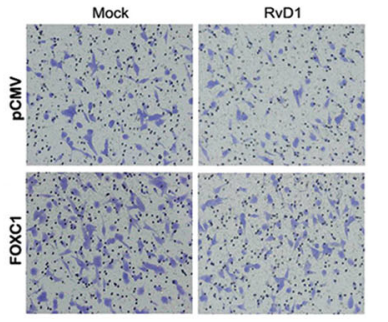

Fig. 5 FOXC1 reverses RvD1/miR-138-mediated suppression of NSCLC cell growth and invasion. a. FOXC1 mRNA expression data were downloaded from the TCGA database containing 439 LUAC cancer tissues. The overall survival (OS) of patients with tumor expressing high vs. low FOXC1 was analyzed by the COX regression test. The relationship between FOXC1 and lymph node metastasis (N0-N3) was analyzed by Kruskal-Wallis test. b. Representative immunohistochemical images of LUSC and LUAC tissues stained with an anti-FOXC1 antibody. Representative in situ hybridization images of lung cancer tissues stained with a miR-138-5p antibody. Scale bars = 50 $\mu m$ (40x). c. A549 cells were transfected with Con, miR-138-5p mimics, pCMV, or FOXC1-pCMV, and then subjected to cell growth and invasion assays. ${ }^{*} P<0.05$, ${ }^{*} P<$ 0.01 compared to Con group; ${ }^{\# \#} P<0.01$ compared to miR-138 group; ${ }^{\$} P<0.01$, compared to FOXC1-overexpressed group. d. A549 cells were transfected with above, and then subjected to cell invasion assays. The transwell units were stained and photographed. High power views (200x) were selected randomly from each sample in a blind manner. e. A549 cells were transfected with Negcon, miR-138 inhibitor, siNC, or siFOXC1,

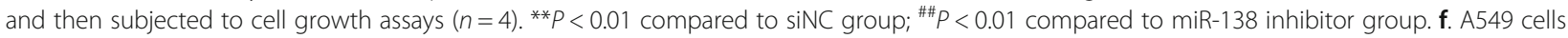
were transfected with above reagents, and subjected to cell invasion assays, and high power views (200x) were selected. g. A549 cells were transfected with pCMV or FOXC1-pCMV, and subjected to cell growth assays $(n=4) .{ }^{* *} P<0.01$ compared to pCMV group; ${ }^{\#} P<0.05$, \#\# $P<0.01$ compared to pCMV+RvD1 $200 \mu \mathrm{g} / \mathrm{L}$ group. ${ }^{\$} P<0.05,{ }^{\$} p<0.01$ compared to FOXC1-overexpression group. $\mathbf{h}$. A549 cells were treated as above and subjected to the invasion assays. The transwell units were stained and high power views (200x) were selected randomly from each sample in a blind manner

5p on cell invasion (Fig. 5c, d). In a parallel experimental scheme, a miR-138-5p inhibitor was transfected in A549 cells with or without the co-transfection of FOXC1 siRNA. Although the miR-138-5p inhibitor stimulated cell growth and invasion as one would expect, the addition of FOXC1 siRNA neutralized all of these effects of this miR-138-5p inhibitor (Fig. 5e, f). Of particular interests to this study, overexpression of FOXC1 in A549 cells significantly promoted cancer cell growth and invasion. Although RvD1 treatment led to $25 \%$ reduction in cell viability, overexpression of FOXC1 significantly attenuated the effect to a $15 \%$ loss of cell viability ability. In cell invasion assay, although RvD1 treatment led to $42 \%$ reduction in lung cancer cell invasion, overexpression of FOXC1 significantly attenuated the effect to a $23 \%$ loss of cell invasive ability. Our data suggested that despite the weak suppressive effects of RvD1 on cell viability and invasion, it was at least partially reversed by overexpression of FOXC1. (Fig. 5g, h). Taken together, these data indicated that miR-138-5p directly targeted FOXC1 to reduce cancer cell growth and invasion.

\section{Endogenous DHA enhances miR-138-5p expression and reduced FOXC1 expression in vivo}

We further established how elevated DHA suppressed tumor growth and metastasis through the regulation of miR-138-5p and FOXC1 in vivo. In situ hybridization and immunohistochemistry assays in the subcutaneous LLC grafts revealed that the level of miR-138-5p level was sharply enhanced, but the expression of FOXC1 significantly attenuated, in the mfat- 1 transgenic mice (Fig. 6a, c). Similar findings were also observed after 


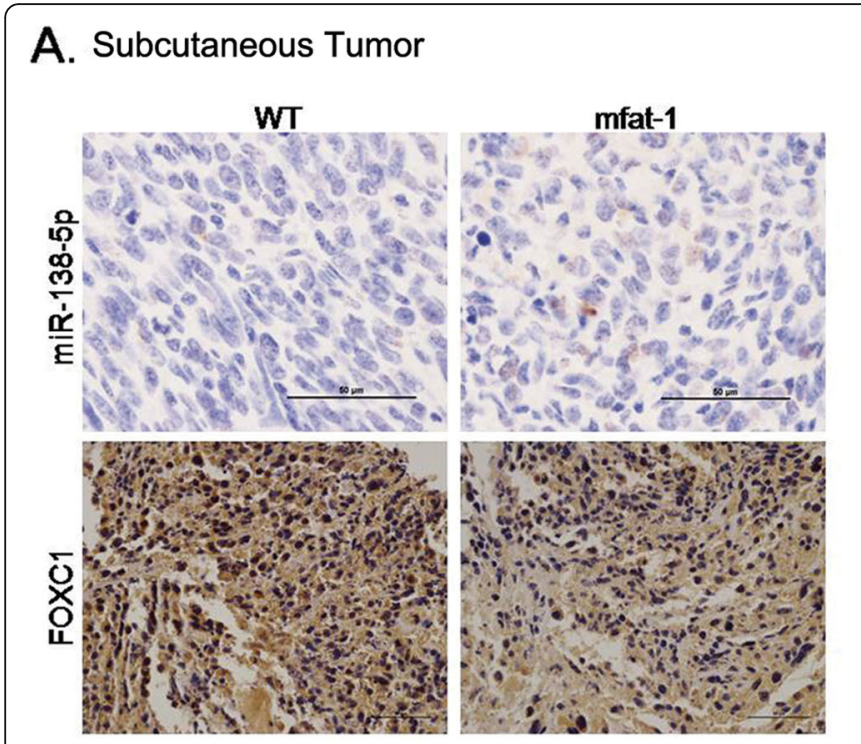

\section{B. Metastatic lung Tumor}

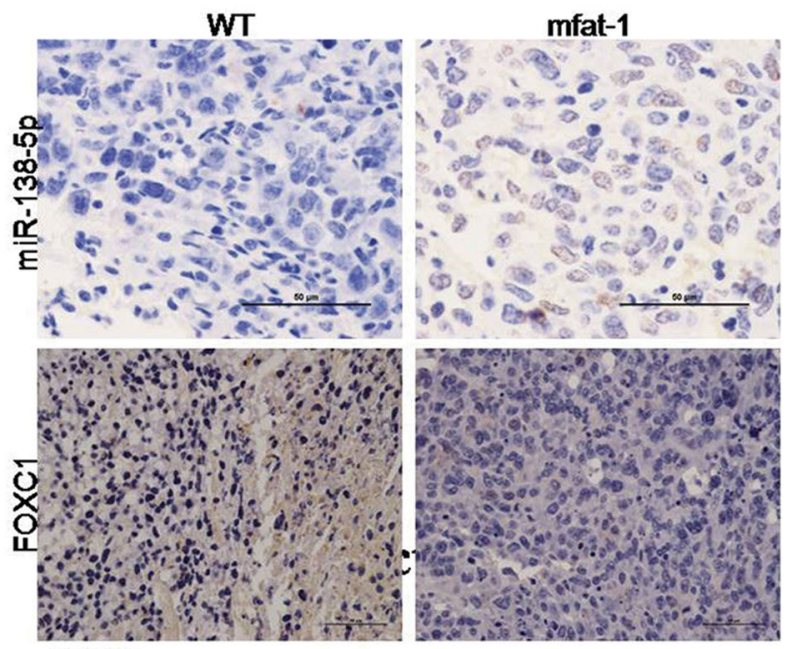

C.
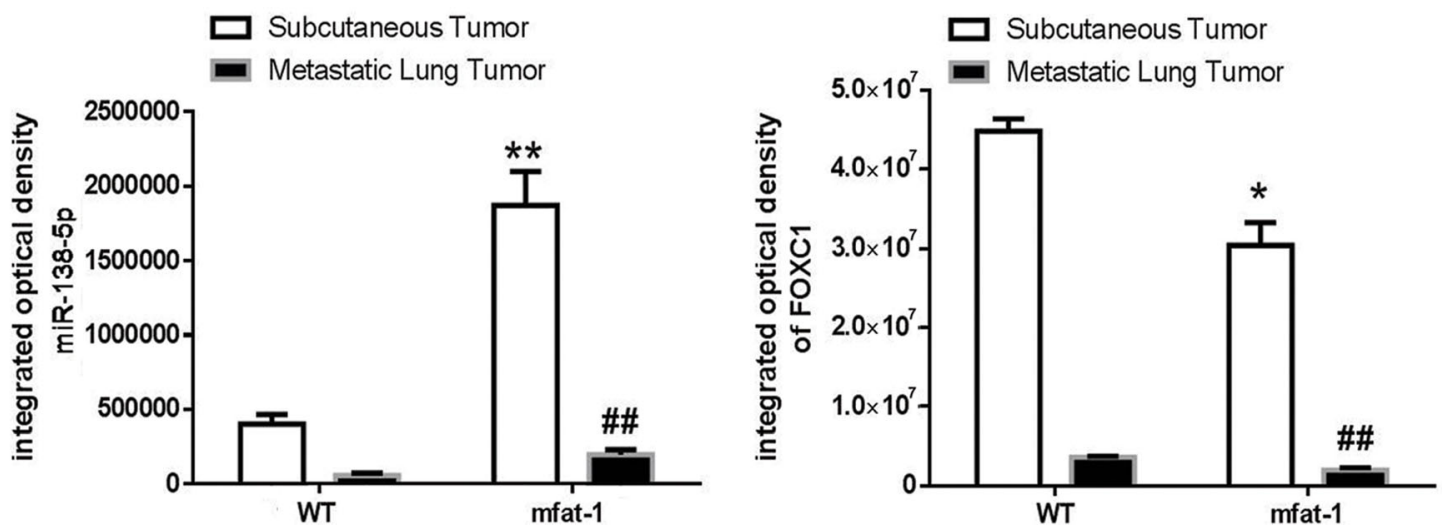

Fig. 6 Endogenous DHA increases miR-138-5p expression and decreases FOXC1 expression in vivo. LLC cells were injected subcutaneously into WT or mfat-1 mice (a), or injected into the tail vein of WT or mfat-1 mice (b). Representative in situ hybridization images of cancer tissues stained with miR-138-5p RNAscope probe (upper panel). Representative immunohistochemical images of LUSC tissues and LUAC tissues stained with an anti-FOXC1 antibody (lower panel). Scale bars $=50 \mu \mathrm{m}(40 \mathrm{x})$. c. The integrated optical density level was determined using Image Pro Plus software. Data are presented as the mean \pm SEM from 4 different samples. ${ }^{*} P<0.05$, ${ }^{*} P<0.01$ for miR-138-5p expression compared to WT group; \#\# $P<0.01$ for FOXC1 expression compared to WT group

analyzing the metastatic lung tumor mass following the intravenous injection of LLC cells (Fig. 6b, c). Elevation of tissue DHA in vivo, therefore, would also cause the same changes in miR-138-5p and FOXC1 as those observed in the cultured lung cancer cells.

\section{Discussion}

Although the current combinatorial immunotherapy has become one of the primary treatment modality for NSCLC, the response rates are still below 30\% [27]. Clinical application of $\omega-3$ PUFA dietary supplement, particularly EPA plus DHA, significantly increased the response rates to chemotherapy and prolonged the survival of cancer patients without affecting the toxicity profiles [28]. A prospective cohort study also showed that DHA intake was inversely associated with lung cancer risk, particularly among never-smokers and adenocarcinoma patients [29]. DHA treatment, both in vivo and in vitro, not only suppressed cancer cell proliferation and migration [9], but also increased cancer cell sensitivity to chemo-drugs [30]. Despite such favorable clinical and cellular evidence, the underlying mechanisms of DHA's actions remain unclear. The current study addressed this issue by revealing that RvD1, one of DHA-initiated eicosanoid metabolites [10], played a critical role in mediating the effects of DHA by decreasing lung cancer cell growth and invasion. Importantly, we found that RvD1 exerted these effects by modulating the miR-138-5p/ FOXC1 pathway in lung cancer cells. 
To this day, little is known about the effects of RvD1 on NSCLC cell growth and metastasis, let alone the underlying mechanisms. We shed some light on this issue by revealing significantly elevated miR-138-5p expression following RvD1 treatment of A549 cells in a miRNA microarray analysis. MiR-138-5p has been reported as a tumor suppressor in several types of cancer such as multiple myeloma and ovarian cancer by targeting EZH2 and survivin $[17,18,31,32]$. Overexpression of miR-138-5p inhibited cancer cell proliferation and invasion while enhancing drug sensitivity [17, 32]. In clinical biopsy samples as well as in TCGA databases analysis, we found that decreased expression of miR-138-5p was frequently observed in metastatic lung cancer tissues, while high miR-138-5p expression was significantly correlated with better prognosis. Overexpression of miR-138-5p reduced, while miR-138$5 \mathrm{p}$ inhibitor promoted, lung cell growth and invasion. Importantly, miR-138-5p inhibitor completely abrogated the anti-tumor effects of RvD1. To our knowledge, this is the first report to establish the mechanistic linkage between miR-138-5p and an eicosanoid metabolite of DHA.

FOXC1 has been highlighted as an important transcriptional regulator involved in diverse tumorigenic processes, such as proliferation, invasion, and angiogenesis [26, 33-35] with high FOXC1 expression associated with poor prognosis in cancer patients [36, 37]. Specifically, in lung cancer, FOXC1 plays a critical role in tumor microenvironmentpromoted cancer progression [38, 39]. Our study has demonstrated FOXC1 as the direct target of miR-138-5p expression. FOXC1 overexpression reversed the suppressive effects of miR-138-5p or RvD1 treatment on lung cell growth and invasion. The elevated miR-138-5p expression induced by DHA treatment could decrease FOXC1 expression in tumor allografts.

\section{Conclusion}

These results built a mechanism linking RvD1, miR-138$5 \mathrm{p}$, and $\mathrm{FOXC1}$ as the signaling pathway that mediated the suppression of NSCLC growth and metastasis by DHA. The revelation of such new mechanism may thus offer a novel treatment target for this malignant disease.

\section{Supplementary information}

Supplementary information accompanies this paper at https://doi.org/10. 1186/s13046-019-1478-3.

Additional file 1: Table S1. Analysis of blood $\omega-6$ and $\omega-3$ PUFA compositions in mfat- 1 transgenic mice. All data presented as means \pm SD. $n=6 .{ }^{*} P<0.05$ and ${ }^{* *} P<0.01$ when compared with the WT group.

Additional file 2: Figure S1. A. The levels of mfat-1 expression were determined by RT-PCR in LLC cells and transgenic mice. B. Levels of overexpression or inhibition of miR-138 were determined by qRT-PCR. All data presented as means \pm SEM. $n=3$. ${ }^{*} P<0.01$ compared to the corresponding control groups. C. The levels of overexpression or inhibition of FOXC1 molecules were determined by Western blot.
Additional file 3: Figure S2. A. A549 or H1299 cells were treated with various concentration of EPA, and were subjected to cell growth assays. B. A549 or H1299 cells were treated with various concentration of EPA, and were subjected to cell invasion assays. Data are presented as the mean $\pm \operatorname{SEM}(n=4) .{ }^{*} P<0.05,{ }^{* *} P<0.01$ compared to $0 \mu \mathrm{M}$ EPA group.

Additional file 4: Figure S3. A. LLC cells were injected into the tail vein of female WT or mfat-1 mice $(n=4)$. Forty days after injection, the mice were euthanized; the lungs were removed and representative images were displayed. B. Metastatic masses were found in other organs in addition to lungs in WT mice. HE-stained tissues were photographed using a Leica microscope. High power views (200x) were selected.

Additional file 5: Figure S4. FOXC1 mRNA expression data were downloaded from the TCGA database containing 479 LUSC cancer tissues. Overall survival (OS) of patients in relation to FOXC1 expression status (high vs. low) was analyzed by the COX regression test. The relationship between FOXC1 expression and lymph node metastasis (NO-N3) was analyzed by Kruskal-Wallis test.

\section{Abbreviations}

Akt: Protein kinase B; DHA: Docosahexaenoic acid; EPA: Eicosapentaenoic acid; Erk: Extracellular regulated kinase; FOXC1: Forkhead Box C1; LCMS: Liquid chromatography separation with tandem mass spectrometry; LUAC: Lung adenocarcinoma; LUSC: Lung squamous cell carcinoma; MiRNAs: MicroRNAs; NSCLC: Non small cell lung cancer;

PUFAs: Polyunsaturated fatty acids; RvD1: Resolvin D1

\section{Acknowledgements}

Not applicable.

\section{Authors' contributions}

$X B$, JS and JP contributed to the conception and design of this study. SZ and ZZ performed the animal experiments. XB collected the human samples. $X B, F L$, and $R X$ performed laboratory experiments. JS analyzed the data. $X B$, $J P$ and $A Z Z$ wrote the manuscript. All authors read and approved the final manuscript.

\section{Funding}

This work was supported in part by grants from the National Natural Science Foundation of China (81630021), the Guangdong Innovative Research Team Program (2016ZT06Y432), and the Startup R\&D Funding from Guangdong University of Technology (50010102). This study was also supported in part by Key Project supported by Medical Science and Technology Development Foundation, Nanjing Department of Health (YKK17209); the Natural Science Foundation of Nanjing Medical University (2016NJMUZD027); the Young Medical Talents of Jiangsu Province (QNRC2016663).

\section{Availability of data and materials}

The datasets supporting the conclusions of this article are included in this published article (and its supplementary information files).

\section{Ethics approval and consent to participate}

All procedures performed in studies involving human participants and animals were approved by the Ethics Committee of the Second Affiliated Hospital of Nanjing Medical University (project license number: 2016KY007). All the patients signed the informed consent form.

\section{Consent for publication}

The authors declare that they agree to submit the article for publication.

\section{Competing interests}

The authors declare that they have no competing interests.

\section{Author details}

'Department of Pathology, Nanjing Medical University, Nanjing 210029, People's Republic of China. ${ }^{2}$ Department of Bioinformatics, Nanjing Medical University, Nanjing 210029, People's Republic of China. ${ }^{3}$ School of Biomedical and Pharmaceutical Sciences, Guangdong University of Technology, Guangzhou 510006, People's Republic of China. ${ }^{4}$ Department of Pathology, The Second People's Hospital of Nantong, Nantong 226000, People's 
Republic of China. ${ }^{5}$ Department of Biotherapy, The Second Affiliated Hospital, Nanjing Medical University, Nanjing 210011, People's Republic of China.

\section{Received: 4 June 2019 Accepted: 11 November 2019}

Published online: 29 November 2019

\section{References}

1. Bray F, Ferlay J, Soerjomataram I, Siegel RL, Torre LA, Jemal A. Global cancer statistics 2018: GLOBOCAN estimates of incidence and mortality worldwide for 36 cancers in 185 countries. CA Cancer J Clin. 2018;68(6):394-424.

2. Siegel RL, Miller KD, Jemal A. Cancer statistics, 2019. CA Cancer J Clin. 2019;69(1):7-34.

3. Chen W, Zheng R, Baade PD, Zhang S, Zeng H, Bray F, et al. Cancer statistics in China, 2015. CA Cancer J Clin. 2016;66(2):115-32.

4. Torre LA, Siegel RL, Jemal A. Lung Cancer statistics. Adv Exp Med Biol. 2016:893:1-19.

5. Connor KM, San Giovanni JP, Lofqvist C, Aderman CM, Chen J, Higuchi A, et al. Increased dietary intake of omega-3-polyunsaturated fatty acids reduces pathological retinal angiogenesis. Nat Med. 2007;13(7):868-73.

6. Fuentes NR, Kim E, Fan YY, Chapkin RS. Omega-3 fatty acids, membrane remodeling and cancer prevention. Mol Asp Med. 2018;64:79-91.

7. Pan J, Cheng L, Bi X, Zhang X, Liu S, Bai X, et al. Elevation of omega-3 polyunsaturated fatty acids attenuates PTEN-deficiency induced endometrial cancer development through regulation of COX-2 and PGE2 production. Sci Rep. 2015;5:14958.

8. Alfano CM, Imayama I, Neuhouser ML, Kiecolt-Glaser JK, Smith AW, Meeske $\mathrm{K}$, et al. Fatigue, inflammation, and omega-3 and omega- 6 fatty acid intake among breast cancer survivors. J Clin Oncol. 2012;30(12):1280-7.

9. Ali M, Heyob K, Jacob NK, Rogers LK. Alterative expression and localization of profilin 1NASPpS157 and Cofilin 1NASPpS239 regulates metastatic growth and is modified by DHA supplementation. Mol Cancer Ther. 2016; 15(9):2220-31

10. Zhang G, Panigrahy D, Mahakian LM, Yang J, Liu JY, Stephen Lee KS, et al. Epoxy metabolites of docosahexaenoic acid (DHA) inhibit angiogenesis, tumor growth, and metastasis. Proc Natl Acad Sci U S A. 2013;110(16):6530-5.

11. Sulciner ML, Serhan CN, Gilligan MM, Mudge DK, Chang J, Gartung A, et al. Resolvins suppress tumor growth and enhance cancer therapy. J Exp Med. 2018;215(1):115-40.

12. Lee HJ, Park MK, Lee EJ, Lee CH. Resolvin D1 inhibits TGF-beta1-induced epithelial mesenchymal transition of A549 lung cancer cells via lipoxin A4 receptor/formyl peptide receptor 2 and GPR32. Int J Biochem Cell Biol. 2013;45(12):2801-7.

13. Li Y, Dalli J, Chiang N, Baron RM, Quintana C, Serhan CN. Plasticity of leukocytic exudates in resolving acute inflammation is regulated by MicroRNA and proresolving mediators. Immunity. 2013;39(5):885-98.

14. Bartel DP. Metazoan MicroRNAs. Cell. 2018;173(1):20-51.

15. Toiyama Y, Okugawa Y, Tanaka K, Araki T, Uchida K, Hishida A, et al. A panel of methylated MicroRNA biomarkers for identifying high-risk patients with ulcerative colitis-associated colorectal cancer. Gastroenterology. 2017;153(6): 1634-46 e1638.

16. Schiewer MJ, Knudsen KE. Not so fast: cultivating miRs as kinks in the chain of the cell cycle. Cancer Cell. 2017;31(4):471-3.

17. Li H, Sheng Y, Zhang Y, Gao N, Deng X, Sheng X. MicroRNA-138 is a potential biomarker and tumor suppressor in human cervical carcinoma by reversely correlated with TCF3 gene. Gynecol Oncol. 2017;145(3):569-76.

18. Yang R, Liu M, Liang H, Guo S, Guo X, Yuan M, et al. miR-138-5p contributes to cell proliferation and invasion by targeting Survivin in bladder cancer cells. Mol Cancer. 2016;15(1):82.

19. Li J, Dong J, Li S, Xia W, Su X, Qin X, et al. An alternative microRNAmediated post-transcriptional regulation of GADD45A by p53 in human non-small-cell lung cancer cells. Sci Rep. 2017;7(1):7153.

20. Wei $D$, Li J, Shen M, Jia W, Chen N, Chen T, et al. Cellular production of $n-3$ PUFAs and reduction of n-6-to-n-3 ratios in the pancreatic beta-cells and islets enhance insulin secretion and confer protection against cytokineinduced cell death. Diabetes. 2010;59(2):471-8.

21. Hudert CA, Weylandt KH, Lu Y, Wang J, Hong S, Dignass A, et al. Transgenic mice rich in endogenous omega-3 fatty acids are protected from colitis. Proc Natl Acad Sci U S A. 2006;103(30):11276-81.

22. Kang JX, Wang J, Wu L, Kang ZB. Transgenic mice: fat-1 mice convert $n-6$ to n-3 fatty acids. Nature. 2004;427(6974):504.
23. Li J, Li FR, Wei D, Jia W, Kang JX, Stefanovic-Racic M, et al. Endogenous omega-3 polyunsaturated fatty acid production confers resistance to obesity, dyslipidemia, and diabetes in mice. Mol Endocrinol. 2014;28(8): $1316-28$.

24. Kang JX. Fat-1 transgenic mice: a new model for omega-3 research. Prostaglandins Leukot Essent Fat Acids. 2007;77(5-6):263-7.

25. Halade GV, Kain V, Serhan CN. Immune responsive resolvin D1 programs myocardial infarction-induced cardiorenal syndrome in heart failure. FASEB J. 2018;32(7):3717-29.

26. Yang Z, Jiang $\mathrm{S}$, Cheng Y, Li T, Hu W, Ma Z, et al. FOXC1 in cancer development and therapy: deciphering its emerging and divergent roles. Ther Adv Med Oncol. 2017;9(12):797-816.

27. Dijkstra KK, Cattaneo CM, Weeber F, Chalabi M, van de Haar J, Fanchi LF, et al. Generation of tumor-reactive T cells by co-culture of peripheral blood lymphocytes and tumor Organoids. Cell. 2018;174(6):1586-98 e1512.

28. Murphy RA, Mourtzakis M, Chu QS, Baracos VE, Reiman T, Mazurak VC. Supplementation with fish oil increases first-line chemotherapy efficacy in patients with advanced nonsmall cell lung cancer. Cancer. 2011; 117(16):3774-80.

29. Luu HN, Cai H, Murff HJ, Xiang YB, Cai Q, Li H, et al. A prospective study of dietary polyunsaturated fatty acids intake and lung cancer risk. Int J Cancer. 2018:143(9):2225-37

30. Yan X, Li P, Zhan Y, Qi M, Liu J, An Z, et al. Dihydroartemisinin suppresses STAT3 signaling and Mcl-1 and Survivin expression to potentiate ABT-263induced apoptosis in non-small cell lung cancer cells harboring EGFR or RAS mutation. Biochem Pharmacol. 2018:150:72-85.

31. Tsukamoto S, Lovendorf MB, Park J, Salem KZ, Reagan MR, Manier S, et al. Inhibition of microRNA-138 enhances bone formation in multiple myeloma bone marrow niche. Leukemia. 2018;32(8):1739-50.

32. Rastgoo N, Pourabdollah M, Abdi J, Reece D, Chang H. Dysregulation of $\mathrm{EZH} 2 /$ miR-138 axis contributes to drug resistance in multiple myeloma by downregulating RBPMS. Leukemia. 2018;32(11):2471-82.

33. Aravalli RN, Greten TF. FoxC1: novel regulator of inflammation-induced metastasis in hepatocellular carcinoma. Gastroenterology. 2015;149(4):861-3.

34. Liu J, Zhang Z, Li X, Chen J, Wang G, Tian Z, et al. Forkhead box C1 promotes colorectal cancer metastasis through transactivating ITGA7 and FGFR4 expression. Oncogene. 2018;37(41):5477-91.

35. Li Q, Wei P, Wu J, Zhang M, Li G, Li Y, et al. The FOXC1/FBP1 signaling axis promotes colorectal cancer proliferation by enhancing the Warburg effect. Oncogene. 2019;38(4):483-96.

36. Ray PS, Wang J, Qu Y, Sim MS, Shamonki J, Bagaria SP, et al. FOXC1 is a potential prognostic biomarker with functional significance in basal-like breast cancer. Cancer Res. 2010;70(10):3870-6.

37. Xia L, Huang W, Tian D, Zhu H, Qi X, Chen Z, et al. Overexpression of forkhead box $\mathrm{C} 1$ promotes tumor metastasis and indicates poor prognosis in hepatocellular carcinoma. Hepatology. 2013;57(2):610-24.

38. Lin YJ, Shyu WC, Chang CW, Wang CC, Wu CP, Lee HT, et al. Tumor hypoxia regulates Forkhead box $\mathrm{C} 1$ to promote lung cancer progression. Theranostics. 2017;7(5):1177-91.

39. Cao $\mathrm{S}$, Wang Z, Gao X, He W, Cai Y, Chen H, et al. FOXC1 induces cancer stem cell-like properties through upregulation of beta-catenin in NSCLC. J Exp Clin Cancer Res. 2018;37(1):220.

\section{Publisher's Note}

Springer Nature remains neutral with regard to jurisdictional claims in published maps and institutional affiliations.

Ready to submit your research? Choose BMC and benefit from:

- fast, convenient online submission

- thorough peer review by experienced researchers in your field

- rapid publication on acceptance

- support for research data, including large and complex data types

- gold Open Access which fosters wider collaboration and increased citations

- maximum visibility for your research: over $100 \mathrm{M}$ website views per year

At $\mathrm{BMC}$, research is always in progress.

Learn more biomedcentral.com/submission 